\title{
A cognitive behavioural family intervention reduced psychiatric morbidity in caregivers of patients with Alzheimer's disease
}

\author{
Marriott A, Donaldson C, Tarrier $N$, et al. Effectiveness of cognitive-behavioural family intervention in reducing the burden \\ of care in carers of patients with Alzheimer's disease. Br J Psychiatry 2000 Jun;176:557-62.
QUESTION: Does a cognitive behavioural family intervention reduce psychological distress and depression in caregivers of patients with Alzheimer's disease, and improve patient symptoms?

Design

Randomised (allocation concealed), blinded (outcome assessors), controlled trial with follow up at 3 months.

\section{Setting}

Old age psychiatric service in 2 NHS trusts in Manchester, UK.

\section{Patients}

42 patient-caregiver dyads. Patients (mean age 77 y, $71 \%$ women) had to meet DSM-III-R criteria for primary degenerative dementia of the Alzheimer type, and had to be living in the community with a caregiver who provided their main support. Caregivers (mean age $64 \mathrm{y}$, $69 \%$ women) had to have General Health Questionnaire (GHQ) scores $\geqslant 5$, indicating psychiatric caseness. Follow up was $98 \%$.

\section{Intervention}

14 patient-caregiver dyads were allocated to the 14 session family intervention, which comprised 3 sessions of caregiver education, 6 sessions of stress management, and 5 sessions of coping skills training. 14 dyads were allocated to the interview control group and received the Camberwell Family Interview (CFI), which was considered to be a 1 session cathartic interview; the family intervention group also received the CFI. 14 dyads were allocated to the no interview control group.

\section{Main outcome measures}

Main outcomes were caregiver psychiatric morbidity (GHQ cut off of 4/5 indicating caseness) and depression (Beck Depression Inventory [BDI]). Secondary outcomes were patient cognitive function, depressive symptoms, psychiatric symptoms and behavioural disturbances, and overall severity of dementia.

Professor A Burns

University Department of

Psychiatry, Withington

Hospital, West Didsbury,

Manchester M20 8LR,

UK. Fax +44 (0) 161

4455305 .

A modified version of this abstract and commentary

appears in

Evidence-Based Mental

Health.

\section{Main results}

At 3 months, fewer caregivers in the family intervention group met the criteria for psychiatric caseness compared with those in the 2 control groups (table); they also had lower (better) scores on the BDI than caregivers in the interview and no interview control groups (BDI scores of $6.3,11.4$, and 11.1, $\mathrm{p}=0.004$ and $\mathrm{p}=0.001$, respectively). Patients in the family intervention group had better

Family intervention $v$ interview and $v$ no interview for caregivers of patients with Alzheimer's disease*

\begin{tabular}{llllll}
$\begin{array}{l}\text { Outcomes at } 3 \\
\text { months }\end{array}$ & $\begin{array}{l}\text { Family } \\
\text { intervention }\end{array}$ & $\begin{array}{l}\text { Interview } \\
\text { control }\end{array}$ & $\begin{array}{l}\text { No interview } \\
\text { control }\end{array}$ & RRR (95\% CI) & NNT (CI) \\
$\begin{array}{l}\text { Met criteria for } \\
\text { psychiatric caseness }\end{array}$ & $23 \%$ & $85 \%$ & - & $73 \%(36$ to 91$)$ & 2 (2 to 5$)$ \\
\hline & $23 \%$ & - & $77 \%$ & $70 \%(27$ to 90$)$ & 2 (2 to 7$)$ \\
\hline
\end{tabular}

${ }^{*}$ Missing data on 2 caregivers. Abbreviations defined in glossary; RRR, NNT, and $\mathrm{Cl}$ calculated from data in article.

func-tioning on activities of daily living than patients in the 2 control groups, but did not differ for cognitive function, depression, psychotic symptoms, behavioural disturbances, or overall severity of dementia.

\section{Conclusion}

A 14 session cognitive behavioural family intervention reduced psychiatric morbidity in caregivers of patients with Alzheimer's disease compared with a 1 session cathartic interview or a no interview control group, and improved patient activities of daily living at 3 months of follow up.

\section{COMMENTARY}

Alzheimer's disease is a major public health problem. ${ }^{1}$ Until it is prevented or substantially controlled, the deleterious effects of caring for relatives with Alzheimer's disease in the community will continue to be an important issue for nurses. This study by Marriott $e t a l$ is an important milestone in a 2 decade research agenda aimed at understanding, managing, and preventing carer distress. ${ }^{2}$ This trial is relevant to nurses working in community or outpatient settings, especially those involved in programme development of geriatric services.

The framework of this cognitive behavioural family intervention is consistent with current stress and coping research. The model focuses on carer characteristics and perceptions of caregiving demands and their ability to cope with them. ${ }^{3}$ Targeting individual carer perceptions and coping styles, within the context of a structured intervention, is probably responsible for the positive carer outcomes and improved daily patient functioning. Unfortunately, the use of specially trained personnel to implement the programme decreases its applicability to many community settings.

As in Marriott et al's trial, previous research has shown important, albeit low, levels of psychological morbidity among carers. Using a robust measure of psychiatric caseness, Marriott et al selected carers with a clinically important level of psychological distress and found that the intervention was potent enough to decrease distress to a non-clinical level.

Despite the strengths of this study, it must be viewed as a preliminary report because of 3 methodological considerations. Despite the clinical and statistical significance of the observed results, a confirmatory trial with a larger sample size is needed. Secondly, such a study should have a longer follow up period that better mirrors the chronic, degenerative nature of this disease. Finally, further research should include an economic evaluation that addresses physical quantities and unit costs of resources, quality of life, and associated health state preference values.

E Ann Mohide, RN, MHSc, MSc Associate Professor, School of Nursing McMaster University, Hamilton, Ontario, Canada

1 Trabucchi M.J Geriatr Psychiatry Neurol 1999;12:29-38. 2 Drebing CE. Alzheimer Dis Assoc Disord 1999;13:S93-100. 3 Donaldson C, Burns A. J Geriatr Psychiatry Neurol 1999;12:21-8. 4 Drummond M.J Rheumatol 1995;22:1403-7. 